\title{
CUERPOS DIVERSOS: UNA APROXIMACIÓN DESDE LA FILOSOFÍA DEL CUERPO DE LAÍN ENTRALGO
}

\author{
MANUEL APARICIO \\ IES Aljara, Murcia
}

\begin{abstract}
RESUMEN: En este artículo exploramos una aproximación al fenómeno humano de la diversidad funcional desde la antropología corporalista de Laín Entralgo. Aunque el modelo social de la discapacidad permitió superar el naturalismo que impregnaba el modelo médico tradicional, sin embargo deja al margen el cuerpo, al que sigue concibiendo como mera entidad biológica. Consideramos que la teoría integral del cuerpo de Laín Entralgo, en sus líneas generales, permite tanto disponer de una caracterización más rica de la diversidad funcional como pensar las bases antropológico-morales del trato cuidadoso y justo con las personas que tienen esta característica.
\end{abstract}

PALABRAS CLAVE: cuerpo; diversidad funcional; vulnerabilidad; modelo social de la discapacidad; Laín Entralgo.

\section{Diversity of bodies: an approximation based on Lain Entralgo's philosophy of body}

ABSTRACT: In this article we explore an approximation of the human phenomenon of functional diversity through Laín Entralgo's corporal-based anthropology. Although the social model of disability enabled the naturalism that impregnated the traditional medical model to be overcome, it nevertheless sidelined the body, which it continues to perceive as a mere biological entity. We consider Laín Entralgo's holistic theory of the body. Generally speaking this allows for a richer characterisation of functional diversity while also thinking of the anthropological and moral bases for the careful, fair treatment of people with this characteristic.

KEY WORDS: body; functional diversity; vulnerability; social model of disability; Laín Entralgo.

\section{INTRODUCCIÓN}

En las últimas décadas ha ido cobrando especial relevancia, tanto en el ámbito de las ciencias sociales como en el campo de la filosofía, la cuestión de la vulnerabilidad y su relación con la moralidad y con la cuestión ético-política de la justicia ${ }^{1}$. Una de las temáticas en que se concreta esta tendencia ha sido la referida a la problemática social vivida por las personas con diversidad funcional ${ }^{2}$.

1 Feito, L., «Vulnerabilidad», en: Anales Sistema Sanitario Navarra, 30 (Supl. 3), 2007: 7-22. Agra, M. X., «Vulnerabilidad, injusticias y cuidados», en: Boladeras, M. (ed.), Bioética: justicia y vulnerabilidad, Editorial Proteus, Cànoves y Samalús, 2013, pp. 49-82.

2 En este trabajo utilizaremos el término «persona con diversidad funcional» en lugar de la expresión "persona con discapacidad». Es un término introducido por A. Palacios y J. Romañach en la obra El modelo de la diversidad, Diversitas, Madrid, 2006. Este término hace referencia a la diferencia, respecto a la mayoría estadística de los miembros de la especie 
Buen ejemplo de ello lo constituyen los trabajos realizados por Alasdair MacIntyre ${ }^{3}$ o Martha C. Nussbaum ${ }^{4}$, en los que queda patente la relevancia moral y política que tiene la «vulnerabilidad corporal $»^{5}$. En dichos trabajos se percibe la influencia de buena parte de las ideas nucleares defendidas por el denominado modelo social de la discapacidad, que, en las últimas décadas, se ha abierto paso frente al modelo médico ${ }^{6}$. El modelo médico, predominante desde la época moderna, concibe la discapacidad como una afección que sufre el cuerpo, causante tanto de los impedimentos que tienen las personas como de las dificultades que dichas personas tienen en las actividades propias de la vida social. Se trata de un modelo biologicista, lo que parece descargar a la sociedad de buena parte de la responsabilidad en las transformaciones favorecedoras de la inclusión social. Lo que subyace en el paradigma médico es una concepción objetivista del cuerpo humano que, además de no tener en cuenta la subjetividad, lo sitúa exclusivamente en el campo de la naturaleza, ajeno a toda caracterización social o cultural. Esta concepción es cuestionada en las últimas décadas del siglo XX. El cambio de paradigma introducido por el modelo social adopta una perspectiva emancipadora y redefine la discapacidad en términos de la injusticia social vivida por las personas cuyos cuerpos tienen un funcionamiento diferente al estadísticamente habitual. Este nuevo paradigma, de notable influencia en la actualidad ${ }^{7}$, introduce una distinción entre «discapacidad» e «impedimento», entendiendo que son las barreras sociales —erigidas por acción o por omisión — las causantes de la discapacidad que tienen las personas con cuerpos con un funcionamiento diferente. Es el diseño de la sociedad lo que impide o dificulta seriamente la inclusión social. A su vez, como bien señala Nussbaum, el diseño imperante en una sociedad depende del modo de entender la inclusión predominante en una sociedad ${ }^{8}$ : son las ideas acerca de

humana, en el funcionamiento de los cuerpos y en las funciones realizadas por los seres humanos. Para una discusión crítica de este cambio terminológico puede verse CANIMAS, J., «¿Discapacidad o diversidad funcional?», en: Siglo Cero, 46 (2), nº 254 (2015) 79-97; EtXeBerRIA, X., La condición de ciudadanía de las personas con discapacidad intelectual, Universidad de Deusto, Bilbao, 2008; Seoane, J. A., "¿Qué es una persona con discapacidad?», en: Ágora. Papeles de Filosofía, 30/1 (2011) 143-161. También se ha usado el término "neurodiversidad», referido a la diversidad mental y la diversidad intelectual: Armstrong, T., El poder de la neurodiversidad, Paidós, Barcelona, 2012.

3 Macintyre, A., Animales racionales y dependientes, Paidós, Barcelona, 2001.

4 Nussbaum, M., El ocultamiento de lo humano: repugnancia, vergüenza y ley, Katz Barpal, Madrid, 2006; Las fronteras de la justicia, Paidós, Barcelona, 2007.

5 En tal sentido, MacIntyre se pregunta: «¿Qué consecuencias tendría para la filosofía moral considerar el hecho de la vulnerabilidad y la aflicción, y el hecho de la dependencia como rasgos fundamentales de la condición humana?», Macintyre, A., o. c., p. 18. En la misma dirección, aunque apuntando en sentido inverso, Nussbaum denuncia, en las obras indicadas en la nota anterior, la ficción del adulto invulnerable presente en el imaginario social de la sociedad liberal occidental.

6 Sobre el modelo social de la discapacidad puede consultarse: BARTON, L. (comp.), Discapacidad y Sociedad, Morata, Madrid, 1998; Palacios, A., El modelo social de la discapacidad: orígenes, caracterización y plasmación en la Convención Internacional sobre los Derechos de las Personas con Discapacidad, Ediciones Cinca, Madrid, 2008.

7 Palacios, A., o. c.

8 Nussbaum, M., Las fronteras de la justicia, Paidós, Barcelona, 2006, p. 129. 
la inclusión las que, proyectadas en las estructuras materiales e institucionales, dificultan o facilitan la inserción de los cuerpos con diversidad funcional.

No obstante, desde el interior del modelo social surgieron voces cuestionando tanto su reduccionismo social como la inadecuada concepción objetivo-naturalista del cuerpo que sostiene. En ese sentido, Liz $\mathrm{Crow}^{9}$ planteó la necesidad de un enfoque renovado del modelo social que reconociera la experiencia subjetiva del cuerpo que tienen las personas con diversidad funcional. Más allá de la constatación objetivonaturalista de los diferentes impedimentos o de las interpretaciones socialmente construidas acerca de los mismos, la propuesta de Crow apunta al ámbito de los significados personales, subjetivos, de los impedimentos. Las experiencias corporales vividas por las personas con diversidad funcional constituyen elementos relevantes de su biografía y de su identidad, complementarias de las experiencias de discapacidad que experimentan debido a un conjunto variado de barreras sociales. Por su parte, Hughes y Paterson ${ }^{10}$ muestran que el modelo social sostiene una concepción objetivista del cuerpo (Körper) que elimina el cuerpo vivido (Leib). Al concebir al cuerpo como puro objeto biológico, el modelo social ignora las dimensiones social, histórica o cultural que también lo caracterizan ${ }^{11}$. Estos autores ven la necesidad de alumbrar una nueva concepción del cuerpo con diversidad funcional. Apoyándose en el enfoque fenomenológico de Merleau-Ponty proponen concebirlo - sin renunciar a su materialidad-como un "agente experimentador» ${ }^{12}$, es decir, como un sujeto encarnado que experimenta el mundo.

En la antropología lainiana podemos encontrar un marco metodológico adecuado, no reduccionista, para pensar el cuerpo con diversidad funcional. En tal sentido, valoramos que la triple perspectiva epistemológica desde la que Laín reflexiona sobre el cuerpo humano pone de manifiesto lo inadecuado de las posiciones reduccionistas ${ }^{13}$ — sean de corte biologista o de corte sociohistóricoque lo convierten en un mero objeto, al tiempo que permite superar la dicotomía natural/social. En este trabajo exploramos la triple perspectiva (objetiva, subjetiva e intersubjetiva) que encontramos en la concepción integral del cuerpo formulada por Laín, al entender que, por un lado, tal ampliación de perspectivas conjura

9 CRow, L., «Nuestra vida en su totalidad: renovación del modelo social de la discapacidad», en: Morris, J. (ed.), Encuentros con desconocidas. Feminismo y discapacidad, Narcea, Madrid, 1997, pp. 229-250.

10 Hughes, B. y Paterson, K., «El modelo social de la discapacidad y la desaparición del cuerpo», en: BARTON, L. (comp.): Superar las barreras de la discapacidad, Morata, Madrid, 2008, pp. 107-123.

${ }_{11}$ Estos aspectos son puestos de manifiesto por la «teoría social del cuerpo». En este campo de estudio pueden incluirse, sin ánimo de exhaustividad, la concepción sociohistórica del cuerpo sostenida por Marx, los estudios antropológicos de Marcel Mauss y de Mary Douglas, la concepción discursiva del cuerpo sostenida por Foucault o el paradigma de la corporeidad de Thomas Csordas.

12 Hughes, B. y Paterson, K., o. c., p. 117.

13 A partir de su aceptación del emergentismo, Laín cuestiona el reduccionismo metodológico: «el valor del reduccionismo queda esencialmente limitado por el hecho de que, considerado un nivel de la materia en su real integridad /.../ su génesis y sus propiedades constituyen un novum no inteligible desde los niveles inferiores», Laín ENTralgo, P., El cuerpo humano. Teoría actual, Espasa-Calpe, Madrid, 1991. 
el peligro de la cosificación del cuerpo en que puede terminar el reduccionismo objetivador; por otro lado, entendemos que su reflexión sobre el encuentro «intercorporal» proporciona las bases antropológico-morales para una reflexión sobre la diversidad corporal abierta a la dimensión moral y política. Comenzaremos este trabajo, en primer lugar, enmarcando la concepción lainiana del cuerpo en el horizonte filosófico contemporáneo. Posteriormente analizaremos las diferentes perspectivas desde las que Laín contempla el cuerpo, apuntando, en cada una de ellas, el modo de concebir la diversidad funcional. Finalmente nos ocupamos del aspecto intersubjetivo del cuerpo señalado por Laín, que, a nuestro juicio, proporciona un acercamiento a la diversidad funcional desde el punto de vista de la interdependencia social, como base antropológico-moral para el trato cuidadoso y justo con las personas con diversidad funcional.

\section{El CUERPO EN El HORIZONTE INTELECTUAL CONTEMPORÁNEO}

Los enfoques neoaristotélicos de la diversidad funcional de MacIntyre y de Nussbaum, pese a sus rasgos diferenciales, apelan a la necesidad de contar con una concepción corporeizada del ciudadano y de tener en cuenta, en el plano político, el reconocimiento de la existencia corporal animal del ser humano. Consideran que es necesario poner de manifiesto la intrínseca vulnerabilidad que caracteriza al cuerpo humano, con el fin de poder abordar una concepción de la justicia que incluya a las personas con diversidad funcional. Ambos autores subrayan la importancia que tiene la existencia de una continuidad natural entre el ser humano y los animales ${ }^{14}$. También consideran que es necesario reforzar la conciencia de la dimensión animal del cuerpo humano para remover viejos hábitos culturales, con vistas a favorecer actitudes de comprensión y respeto hacia las personas con diversidad funcional. En su obra Animales racionales y dependientes, MacIntyre subraya la identidad animal del ser humano, el cual se reconoce como un ser cuya vida se estructura en diferentes etapas (infancia, madurez y senectud), en algunas de las cuales presenta algún tipo de diversidad funcional o dependencia. MacIntyre no concibe esta característica como un rasgo particular que atañe a ciertos seres humanos, sino como una cualidad universal de la condición humana ${ }^{15}$, ligada a la corporalidad. Entiende que la diversidad funcional física y la diversidad funcional mental

son aflicciones del cuerpo; por lo tanto, los hábitos de pensamiento que expresan una actitud de negación de la discapacidad y la dependencia implican una incapacidad para reconocer la importancia de la dimensión corporal de la existencia, o incluso el rechazo de dicha dimensión ${ }^{16}$.

14 Macintyre, A., o. c., pp. 25-26; Nussbaum, M., Las fronteras de la justicia, o. c., p. 358.

15 MacIntyre indica que "es importante recordar que existe una escala de discapacidad en la que todos ocupamos un lugar. La discapacidad es, en su grado y en su duración, una cuestión de más y menos. En diferentes momentos de la vida, y a menudo de manera impredecible, todos podemos vernos situados en puntos muy diferentes de la escala», Ibid., pp. 91-92.

16 Ibid., pp.18-19. 
El ser humano tiene unas posibilidades de florecimiento ${ }^{17}$ cuyos límites vienen dados por su pertenencia a la especie humana. A su vez, este tipo de florecimiento define la naturaleza de la vulnerabilidad corporal que puede afectarle. Una correcta autocomprensión de esta base natural constituye, para MacIntyre, un requisito indispensable para entender el fenómeno del cuerpo con diversidad funcional y para construir una sociedad justa con quienes tienen cuerpos que funcionan de modo diferente al habitual. La asunción de la condición animal propia de cualquier ser humano ha de tener consecuencias en el desarrollo de la moralidad y en el modo de entender la sociedad política ${ }^{18}$, que debería ser organizada de modo que se ajustara a las necesidades que tienen los ciudadanos en tanto que miembros de la especie humana, en la medida en que - al menos en algunos momentos de su vida - todos los seres humanos se enfrentan, en mayor o menor grado, a la vulnerabilidad corporal y la dependencia. Por su parte, Nussbaum retoma el planteamiento de MacIntyre y denuncia el carácter ficticio del sujeto ético-político que subyace en las concepciones contractualistas de la justicia. A su juicio, el uso del «mito del ciudadano como adulto independiente» ${ }^{19}$ por parte de la tradición contractualista, incluida la versión kantiana de Rawls, oculta las etapas de la vida en las que todo ciudadano depende asimétricamente de otros. Por eso, su enfoque de las capacidades revisa a fondo la teoría de la justicia rawlsiana. La filósofa norteamericana defiende una concepción política compleja del ciudadano, definido como «ser capaz y necesitado» y sostiene una concepción de la justicia dirigida «a una sociedad que busca reconocer la condición humana (que incluye la animalidad, la mortalidad y la finitud) en vez de ocultarse de ella» ${ }^{20}$.

La apelación que, de un modo u otro, dichos autores hacen al pensamiento de Aristóteles supone la adopción de una perspectiva naturalista del cuerpo humano que, a nuestro juicio resulta insuficiente. En tal sentido, cabe recordar que Aristóteles ya definió al ser humano como zoon politikón ${ }^{21}$, conocida fórmula con la que aúna la animalidad del ser humano con su inserción en el ámbito social y político, si bien situaba ambos (tanto la corporalidad animal del ser humano como el ámbito político de la ciudad) en el campo de la naturaleza (physis). Para el Estagirita, en el ser humano confluyen, en virtud del logos que permite el acceso a un sentido de justicia, su condición biológica y su condición de ciudadano. Es esta dimensión social y política, interpretada desde la naturaleza, desde donde el animal constituido de forma lingüística y racional puede vivir bien, satisfaciendo así, de acuerdo con criterios de justicia, sus necesidades vitales. Sin embargo, desde la Modernidad se abre un nuevo horizonte ${ }^{22}$ muy diferente al puramente

$17 \quad$ Ibid., pp. 82-83.

18 Ibid., p. 154.

19 Nussbaum, M.: El ocultamiento de lo humano, o. c., p. 356.

$20 \quad$ Ibid., p. 391.

21 Aristóteles, Política, Gredos, Madrid, 1988.

22 Conill, J., “¿Regreso a la "naturaleza humana”? Una reflexión bioética», en: LóPEz DE LA Vieja, M. T. (ed.), Bioética. Entre la Medicina y la Ética, Ediciones Universidad de Salamanca, 2005, pp. 101-113. Distingue Conill, recogiendo lo expresado por Zubiri, entre el horizonte metafísico griego, de carácter naturalista, y el horizonte metafísico moderno, centrado en la «persona». 
naturalista defendido por Aristóteles. Aunque este nuevo horizonte no ignora la dimensión biológica del cuerpo, se centra en la persona y su relación intersubjetiva con los otros, lo que pone en relación al cuerpo con el mundo social y cultural. Un claro ejemplo actual de una concepción del cuerpo situada en este nuevo horizonte lo encontramos en el Habermas de El futuro de la naturaleza humana. Resulta sintomático que Habermas reformule la caracterización aristotélica del ser humano como zoon politikón, reuniendo la dimensión animal con la personal: «el ser humano es un animal que, gracias tan solo a su inserción originaria en una red pública de relaciones sociales, desarrolla las competencias que le convierten en persona ${ }^{23}$. Cuerpo y persona están, pues, entrelazados: Habermas, asumiendo la distinción fenomenológica de H. Plessner entre «tener cuerpo» (Körper) y "ser cuerpo» (Leib), concibe a la persona como subjetividad encarnada, y al cuerpo como envoltura física de la subjetividad personal ${ }^{24}$.

La concepción lainiana del cuerpo también se inserta claramente en este nuevo horizonte personalista. Su teoría integral del cuerpo humano constituye una teoría antropológico-filosófica que toma como centro al cuerpo y que concibe al ser humano como «materia personal» ${ }^{25}$. Es, pues, una «antropología personalista» que revaloriza el cuerpo humano al unir su materialidad con el carácter personal, propio de la realidad humana, surgido por un salto emergente a partir de aquella. La concepción antropológica de Laín no niega, pues, la existencia de la «naturaleza humana», sino que lo que rechaza es el puro naturalismo:

«El hombre es a la vez naturaleza y persona; desde un punto de vista, es naturaleza personal, y desde otro, como X. Zubiri y G. Marcel suelen decir, espíritu encarnado. La empresa de conocer y tratar a un hombre en cuanto tal, requiere considerar a la vez lo que en la realidad humana es naturaleza y lo que en ella es persona; tanto más, cuanto que el hombre es naturaleza y persona de un modo unitario, solidario e indisoluble ${ }^{26}$.

Laín rechaza el «naturalismo antropológico» ${ }^{27}$, según el cual la realidad humana se agota en las operaciones físicas o psicosomáticas. Se opone a un naturalismo que ve la libertad, la responsabilidad y la moralidad como meras manifestaciones epifenoménicas de la naturaleza humana. La teoría lainiana del cuerpo, de corte personalista, aporta una visión pluridimensional del cuerpo humano, superadora del reduccionismo naturalista. A nuestro juicio, uno de los méritos relevantes de su concepción antropológica lo constituye su propuesta de un marco metodológico integral, abarcador de las diferentes perspectivas (objetiva, subjetiva e intersubjetiva) desde las que puede contemplarse el cuerpo humano. Este marco integral permite una más rica aproximación al fenómeno humano de la diversidad funcional: a) como afección psicoorgánica plasmada en el modo diferente o en la imposibilidad de rea-

23 Habermas, J., Entre naturalismo y religión, Paidós, Barcelona, 2008, p. 21.

24 Habermas, J., El futuro de la naturaleza humana, Paidós, Barcelona, 2009.

25 Laín Entralgo, P., El cuerpo humano. Teoría actual, o. c., pp. 323-325.

26 Laín Entralgo, P., Ser y conducta del hombre, Espasa Calpe, Madrid, 1996, pp. 181-182. Aunque con diferencias, el «naturalismo blando» de Habermas también trata de compaginar naturaleza y espíritu, concibiendo al ser humano como «espíritu encarnado». Puede verse: Habermas, J., Entre naturalismo y religión, o. c.

27 Laín Entralgo, P., Ibid., p. 172. 
lizar una conducta que tiene la persona, b) como un conjunto de vivencias subjetivas y c) en el plano intersubjetivo de la relación yo-tú, como un rostro que demanda cuidado y justicia. La articulación de tales perspectivas tiene, a nuestro juicio, consecuencias importantes en la comprensión del fenómeno de la diversidad corporal: detrás de la vulnerabilidad psicofísica hay un sujeto que experiencia el mundo físico y social y que, de un modo u otro, está abierto al ámbito de relaciones interpersonales que constituyen la comunidad moral y política. Corresponde a esta ofrecer un cuidado humanizador de la vulnerabilidad psicofísica y reconocer la igual dignidad y los derechos de las personas con cuerpos diversos, con vistas al desarrollo de sus vidas ${ }^{28}$.

\section{AMBIGÜEDAD, UNICIDAD Y PLURIDIMENSIONALIDAD CORPORAL}

Laín adopta el paradigma conductual del cuerpo ${ }^{29}$, construyéndolo a partir de un amplio bagaje de conocimientos científicos (anatomía, fisiología, biología molecular, etc.), encuadrados en el ámbito de las ciencias naturales, aunque también apunta, si bien no lo desarrolla, la necesidad de recurrir a la psicología o la sociología ${ }^{30}$. Incorpora también las aportaciones de la tradición fenomenológica (Husserl, Marcel, Sartre, Merleau-Ponty u Ortega y Gasset) y la influencia recibida de la metafísica de la persona de X. Zubiri. Para Laín, entender exhaustivamente lo que es el cuerpo humano solo es posible desde el nivel de la conducta, concebida esta como "acción intencional en el mundo» ${ }^{31}$. Laín adopta la distinción KörperLeib procedente de la tradición fenomenológica. Cabe señalar que tal distinción no supone la defensa de una especie de dualismo ontológico. Por el contrario, la concepción fenomenológica del cuerpo permite la integración unitaria de las estructuras objetivas (Körper) que pueden ser descritas en términos científicos con las vivencias experienciadas subjetivamente (Leib). No cabe el dualismo porque ambas son «dos dimensiones del cuerpo vivido, que es también un cuerpo de carne y hueso, nervios, fibras, que puede ser descrito científica y objetivamente» ${ }^{32}$. Estamos, más bien, ante la existencia de dos perspectivas epistemológicas:

«La experiencia del cuerpo vivido combina las perspectivas científicas de la tercera persona con la descripción fenomenológica en primera persona. Experiencio mi cuerpo como una dimensión subjetiva y como un objeto entre los objetos, como Leib y Körper, cuerpo vivo y cuerpo vivido» ${ }^{33}$.

28 Esta integración de perspectivas, aunando la materialidad corporal y la subjetividad personal, es una cuestión relevante en la actualidad, como queda evidenciado en el debate contemporáneo producido a partir de la propuesta de mejoramiento humano. Para una visión del tema aplicada a los cuerpos con diversidad funcional puede verse: Cortina, Albert y Serra, Miquel-Àngel, Singulares. Ética de las tecnologías emergentes en personas con diversidad funcional, Ediciones internacionales universitarias, Madrid, 2016.

29 Laín Entralgo, P., El cuerpo humano. Teoría actual, o. c.

$30 \quad$ Ibid., pp. 312-313.

31 Ibid., p. 191.

32 ORTEGA, F., El cuerpo incierto. Corporeidad, tecnologías médicas y cultura contemporánea, CSIC, Madrid, 2010, p. 33.

33 Ortega, F., Ibid., p. 69. 
La descripción conductual del cuerpo humano de Laín asume la existencia de tales perspectivas, en la medida en que toma como punto de partida la ambigüedad ${ }^{34}$ instalada en las mismas. Si se parte de la perspectiva del cuerpo visto, entonces el propio cuerpo (o el cuerpo del otro) se presenta como un objeto que puede ser contemplado cuando ejecuta ciertas conductas. Pero, por otra parte, dicho cuerpo (el mío o el de otro) también se presenta como sujeto que es el autor y ejecutor de tales conductas. Si, por el contrario, se parte de la perspectiva del cuerpo vivido también encontramos dicha ambigüedad: cuando percibimos el cuerpo propio lo captamos como un objeto que podemos observar exteriormente; aunque también lo captamos como una parte integral de nuestra actividad subjetiva, en el caso de sentirlo internamente. Laín muestra, con su análisis de la ambigüedad, la reversibilidad tematizada por la fenomenología entre «tener cuerpo" y "ser cuerpo», según se adopte la perspectiva de la tercera persona (como él, en tanto que objeto) o la perspectiva de la primera persona (como yo, en tanto que sujeto). Esta doble perspectiva resulta compatible con la unicidad del propio cuerpo:

«Mi cuerpo es ahora, en efecto, dos cosas distintas: es, por una parte, lo que de él percibo cuando miro la mano que está escribiendo estas palabras /.../es, por otra parte, lo que se me hace patente en la leve sequedad que en este momento siento en mi boca» ${ }^{35}$.

En la actualidad se justifica la existencia de esta doble perspectiva defendida por Laín desde distintas áreas científicas:

a) Desde el campo de la neurociencia, Damasio ${ }^{36}$ aborda el proceso filogenético del surgimiento de la mente y de la conciencia. Damasio pone de manifiesto el papel que juega la capacidad cartográfica del cerebro en la aparición de la mente dotada de subjetividad. Para poder gestionar mejor el cuerpo vivo, el cerebro construye mapas de las estructuras y del estado funcional del cuerpo. Es esta capacidad cartográfica cerebral lo que hace posible que el cuerpo se convierta en un objeto contenido en la mente. El surgimiento de la mente hizo posible la regulación del cuerpo mediante el uso de imágenes, lo que posibilitó la aparición de las sensaciones corporales. Finalmente, el proceso evolutivo llevó al surgimiento de la conciencia, la cual hizo factible el conocimiento del organismo vivo y la emergencia de la subjetividad.

b) Apoyándose en la psicología cognitiva, Habermas ${ }^{37}$ explica la articulación ontogenética de estas perspectivas, mostrando el carácter primario que tiene el «ser cuerpo» (Leib) sobre el «tener cuerpo» (Körper). Lo primario, según Habermas, es la experiencia del propio cuerpo. Esta es, al mismo tiempo, la experiencia de la subjetividad de la persona. A partir de esta surgirá, en la evolución psicológica del adolescente, el tener cuerpo, al contemplarlo de modo objetivo, adoptando la perspectiva del observador. El individuo es capaz, desde esta etapa de su vida, de tomar la perspectiva de la tercera persona, observando su propio cuerpo como un objeto situado entre otros objetos.

34 Laín Entralgo, P., El cuerpo humano. Teoría actual, o. c., pp. 282-284.

35 Ibid., p. 120.

36 Damasio, A., Y el cerebro creó al hombre, Destino, Barcelona, 2010.

37 Habermas, J., El futuro de la naturaleza humana., o. c., p. 71. 
Otro aspecto de interés en la teoría del cuerpo de Laín es que pone de relieve la importancia del cuerpo en relación al encuentro ${ }^{38}$ intersubjetivo con el otro: «El cuerpo, o, mejor, la corporalidad, viene a ser así el supuesto de los supuestos de la relación y del encuentro» ${ }^{39}$. Dicha inter-corporalidad surge de la experiencia práctico-vital, "porque yo soy mi cuerpo y porque hago mi vida entre los cuerpos de los demás ${ }^{40}$. Con ello, Laín estaría señalando no solo que la corporalidad es aquello que nos constituye, sino que, además, también es aquello que primigeniamente nos vincula con los demás. Puede decirse que cualquier otro tipo de vinculación - como en el caso de la vinculación moral o la vinculación sociopolítica-, en la medida en que es dependiente de aquella vinculación vital con los otros, ha de tener en cuenta dicha corporalidad. La relación intersubjetiva de carácter moral o de carácter político ha de ser entendida, por tanto, como una relación entre sujetos encarnados. Es decir, como una relación, a la vez, intercorporal e intersubjetiva.

En el encuentro con el otro también se produce el fenómeno de la ambigüedad. El otro puede contemplarse desde la perspectiva de la tercera persona, siendo él, siendo "otro que yo». También puede contemplarse, por su semejanza con lo que yo soy, desde la perspectiva de la segunda persona: siendo tú, es decir, siendo «otro como yo». Ambas perspectivas son posibles a partir del encuentro inter-corporal. La doble perspectiva epistemológica que puedo adoptar en relación al cuerpo del otro se funda en la condición corporal del nosotros, es decir, en la inter-corporalidad que caracteriza al encuentro intersubjetivo. Desde un punto de vista fenomenológico dirá Laín que

«lo que se nos presenta con esa subitaniedad y esa inmediatez no es el «otro» como tal, sino un "nosotros" que rápidamente, y tan pronto como yo tomo actitud frente a la situación creada por ese relámpago perceptivo — tan pronto como yo "me rehago" según la vigorosa expresión popular- se descompone en un tú y un yo»"

El nosotros se constituye, según Laín, en el encuentro interhumano — sea un encuentro con otra persona o un encuentro abierto al conjunto de la humanidadque es siempre un encuentro inter-corporal. Este encuentro es el que funda la doble perspectiva, como él o como tú, desde la que podemos vivenciar al otro ${ }^{42}$. En el encuentro puedo objetivar al otro, incluso hasta el extremo de dejar de considerarlo «otro como yo». Laín pone como ejemplos de este trato deshumanizador del otro el racismo y el fanatismo político o religioso ${ }^{43}$. Podríamos añadir también el fenómeno de la estigmatización de las personas con diversidad funcional: en el trato deshumanizador que subyace a la estigmatización hay un intento de pensar que, en virtud de las diferencias corporales existentes, "yo no soy como

38 Laín Entralgo, P., Teoría y realidad del otro, II, Revista de Occidente, Madrid, 1968.

39 Ibid., p. 45.

40 Laín Entralgo, P., El cuerpo humano. Teoría actual, o. c., p. 132.

41 Laín Entralgo, P., Teoría y realidad del otro, II, o. c., p. 77.

42 "El levísimo nosotros que se desdobla en él y yo (él: un tú posible) y el nosotros intenso que se desgrana en tú y yo son, a mi juicio, y en la medida en que una vivencia pueda ser comparada con otra, cualitativamente equiparables entre sí», Ibid., p. 79.

43 Laín Entralgo, P., Ser y conducta del hombre, Espasa, Madrid, 1996, pp. 317, nota 11. 
el otro» y, por tanto, que no estoy ante «otro como yo». Iris M. Young también ha puesto de manifiesto esta doble perspectiva señalada por Laín: «El encuentro con la persona discapacitada produce otra vez la ambigüedad de reconocer que la persona a la que proyecto tan diferente, tan otra, es sin embargo como yo» ${ }^{44}$, lo que puede desencadenar, como mecanismo protector de mi yo, la estigmatización de quien exhibe su vulnerabilidad en el encuentro intercorporal ${ }^{45}$. No obstante, también puede desarrollarse con el otro una serie, más o menos continuada, de interacciones personales. En ese sentido, podría darse, como señala MacIntyre, una actitud empática: puedo pensar que la persona con diversidad funcional con la que me encuentro "podría haber sido yo" ${ }^{46}$. Lo cual supone el reconocimiento de que estoy en presencia de "otro como yo", que yo también me identifico como un ser corporalmente vulnerable. Tal identificación es la base para el cuidado del otro y para la construcción de una sociedad política inclusiva.

A nuestro entender este carácter primigenio de la vivencia del nosotros que, según Laín, se da en el encuentro inter-corporal, tiene relevancia en relación al reconocimiento normativo del otro. El encuentro inter-corporal, como vivencia previa del nosotros, constituye la base para el reconocimiento mutuo, en el que cada cual, de modo derivado, reconoce al otro como un tú, como otro como yo. Lo cual supone, por un lado, que el reconocimiento recíproco de un yo y un tú, producido entre sujetos encarnados, se hace desde el cuerpo que cada uno $\mathrm{es}^{47}$. A su vez, tal reconocimiento del otro no puede eludir el carácter material de la persona. Es decir, ha de incluir tanto el funcionamiento corporal diverso, la vulnerabilidad corporal que cada uno pueda tener, como las vivencias subjetivas — dadas a conocer en el encuentro- de tal corporalidad, abiertas como están, a su vez, a la influencia intersubjetiva.

Un último aspecto que encontramos en la "antropología corporalista» ${ }^{48}$ de Laín es el que se refiere al carácter pluridimensional del cuerpo. Cuerpo y yo no son, para este pensador, realidades contradistintas sino que se encuentran fundidas en una única realidad:

44 Young, I. M., La justicia y la política de la diferencia, Cátedra, Madrid, 2000, p. 247.

45 Recientemente, Adela Cortina considera que la estigmatización de las personas con diversidad funcional puede encuadrarse como una variante de la aporofobia, entendiendo por tal, en un sentido amplio, el «desprecio y rechazo en cada caso de los peor situados, que pueden serlo económicamente, pero también socialmente». CorTina, A., Aporofobia, el rechazo al pobre, Paidós, Barcelona, 2017, p. 43. A su juicio, la base neurobiológica de tal forma de rechazo radica en una evolución de las estructuras cerebrales, que ha seleccionado el trato con los cercanos y rechazado el trato con los extraños. Consecuentemente, la única forma de revertir esta tendencia, dada la plasticidad cerebral, es el fomento de una educación y de un entramado institucional que reconozca a los peor situados en la sociedad (o. c., pp. 72-81).

46 «De quienes padecen una lesión cerebral, o han sufrido una grave incapacidad de movimiento o son autistas, de todos ellos hace falta decir: podría haber sido yo. La desgracia de esas personas podría haber sido la de cualquiera, la buena suerte de otras podría haber sido la suya», Macintyre, A., Animales racionales y dependientes, o. c., p. 121.

47 Laín Entralgo, P., Teoría y realidad del otro, I, Revista de Occidente, Madrid, 1968, p. 125.

$48 \quad$ Ibid., p. 385. 
"No "mi cuerpo y yo", sino "mi cuerpo: yo". No la autoafirmación de un "yo"para el cual algo unidísimo a él, pero distinto de él, el cuerpo, fuese dócil o rebelde servidor -implícitamente, eso lleva dentro de sí la expresión "mi cuerpo"-, sino la autoafirmación de un cuerpo que tiene como posibilidad decir de sí mismo "yo" »"

La concepción antropológica desarrollada por Laín, identifica el cuerpo propio con el yo que cada uno ha llegado a ser. Entiende que en el cuerpo propio confluyen una variedad de procesos genéticos emergentes que van configurándolo ${ }^{50}$ : cosmogénesis, filogénesis, ontogénesis, devenir histórico y proceso biográfico. Con su teoría integral del cuerpo defiende Laín un monismo emergentista, según el cual la realidad material del organismo da lugar a la aparición de las estructuras humanas: lo psíquico, lo sociocultural y lo histórico. En último término, el cuerpo humano es materia personal, une de modo indiviso lo orgánico y lo psíquico. En virtud de que el cuerpo propio - mi cuerpo- es subjetividad encarnada, yo encarnado, cabe establecer la dependencia de la propia corporalidad de las diferentes dimensiones (física, biológica, social, cultural, histórica, personal) que moldean aquello que soy. Podemos decir que la corporalidad vendría a ser, para Laín, una especie de crisol en el que quedan recogidas las diferentes dimensiones (natural, sociohistórica, subjetivo-personal) que, fundidas de un modo singular, configuran lo que somos. El momento histórico, la sociedad y la cultura (hábitos sociales y psicológicos, lenguaje, etc.), junto a la base material física y orgánica — también sujeta a la transformación histórico-social—, contribuyen a moldear el cuerpo personal que somos a través de la estructura corporal del cerebro:

«Todo ello en mi cuerpo, en el cuerpo que yo era, porque mis sentidos corporales y mi cerebro recibieron la impronta de tales noticias, y porque en la constitución y en la actividad de esos circuitos cerebrales, no en las enigmáticas operaciones de un alma espiritual, tuvieron su verdadera realidad los hábitos así establecidos en mi vida personal ${ }^{51}$.

El cuerpo que yo soy, mi identidad personal, está constituida tanto por mi organismo vivo como por la influencia de la relación con los otros dada histórica y socialmente. En la formación de esa identidad personal juega un papel fundamental el cerebro, como base orgánica que facilita la ejecución de mis acciones, a través de las cuales voy configurando mi biografía. Desde una perspectiva neurofilosófica actual, Adela Cortina refuerza esta idea señalando que numerosos estudios recientes «muestran que el cerebro humano se va conformando en relación con los otros, que es social, y por eso podemos decir que somos en relación, que el individualismo es falso por abstracto ${ }^{52}$.

49 Laín Entralgo, P., Ser y conducta del hombre, o. c., pp. 351-352.

$50 \quad$ Ibid., pp. 366-389.

$51 \quad$ Ibid., p. 383.

52 Cortina, A., (ed.), Guía Comares de neurofilosofía práctica, Comares, Granada, 2012. Habermas pone de manifiesto que es la socialización intersubjetiva por medio del lenguaje la que explica la interrelación entre los cerebros individuales y los programas culturales existentes en un medio sociohistórico. Habermas, J., Naturalismo y religión, o. c., pp. 159-187. 


\section{Perspectivas del CUERPO Y DiVERSIDAd FUnCIONAL}

Laín señala tres facetas fundamentales del cuerpo humano: las estructuras objetivas, las vivencias subjetivas y su carácter de realidad moral intersubjetiva. Muestra que el cuerpo humano, más allá de su originaria realidad física, se eleva al plano de la acción y, en último término, se nos revela en su carácter personal, quedando abierto a la intersubjetividad. Encontramos que, en su teoría conductual del cuerpo, además de incorporar la reversibilidad fenomenológica entre cuerpo objetivo (Körper) y cuerpo vivido (Leib), recoge también la integración de las estructuras biológicas con la historia biográfica de la persona, en la que se configura la propia identidad. Todo ello, a su vez, enmarcado en la relación inter-corporal e intersubjetiva entre un yo y un tú, poniendo en conexión al cuerpo humano, como materia personal, con la apertura moral a la alteridad. En este apartado, tratamos de conceptualizar la noción de diversidad funcional, poniéndola en relación con esas tres perspectivas del cuerpo.

El paradigma conductual del cuerpo defendido por Laín recoge los planteamientos filosóficos de Zubiri (cuerpo como soma), de la tradición fenomenológica de Ortega, Marcel o Merleau-Ponty (cuerpo como carne) y de la filosofía de Lévinas (cuerpo como rostro). Aún reconociendo que somos constitutivamente cuerpo y entendiendo el cuerpo, al modo fenomenológico, como experiencia vivida (Leib), la concepción lainiana del cuerpo no prescinde del acercamiento objetivista a él (Körper) proporcionado por los saberes científicos. Su concepción unitaria del cuerpo se aleja así del puro subjetivismo y el puro objetivismo, por cuanto la actividad propia del cuerpo «tiene que ser a la vez conducta humana y autopercepción íntima» ${ }^{53}$. Por otra parte, el encuentro inter-corporal es un encuentro interpersonal en el que se hace patente la presencia ética de la alteridad del otro, el encuentro con el otro en tanto que otro. Veamos esa triple perspectiva del cuerpo desarrollada por Laín y su repercusión en el acercamiento al fenómeno de la diversidad funcional:

1) Laín continúa la tradición fenomenológica. Desde esa óptica, el cuerpo (Leib) es experiencia vivida, es experiencia de mi cuerpo. Laín señala algunos rasgos de esta vivencia del cuerpo, de entre los cuales podemos destacar los siguientes ${ }^{54}$ :

a) Conciencia de mi identidad en el tiempo: porque soy mi cuerpo, poseo una identidad por la cual sigo siendo "el mismo», aunque no sea siempre «lo mismo». En esta identidad encontramos dos componentes: uno permanente, que hace que sea «el mismo», y otro que es cambiante, por el cual no soy «lo mismo». Dado el carácter histórico de la vida, por mi cuerpo tengo conciencia de una identidad a la vez continua y cambiante.

b) Conciencia de mi actividad: de la experiencia inmediata de mi cuerpo se deriva la conciencia de «mi poder», aunque también la conciencia de «mi limitación». Sin cuerpo no habría la conciencia de la doble posibilidad «yo puedo-yo no puedo». Mi cuerpo se manifiesta como fuente de impulsos (que nos mueven a la acción), como conjunto de instrumentos (para poder ejecutarla), y como aquello que me posibilita

53 Laín Entralgo, P., El cuerpo humano. Teoría actual, o. c., p. 195.

54 Ibid, Cap. IV. 
y también me limita (lo que me dificulta o impide hacer algo). También es causa de sentimientos $^{55}$ (me informa de los estados cambiantes de mi cuerpo: fatiga, dolor, sufrimiento, etc.).

c) Conciencia de mi expresividad: la vivencia de mi cuerpo situado entre otros cuerpos me hace consciente del poder expresivo ${ }^{56}$ de mi cuerpo a través del lenguaje, la mirada, los gestos o el silencio. El cuerpo tiene, en el encuentro interhumano, un poder comunicador en virtud del cual, de uno u otro modo, comunico al otro - al menos en parte- lo que soy.

Desde esta perspectiva subjetiva del cuerpo, habría que entender la diversidad funcional como parte de la vivencia corporal de la persona y, como tal, como aquello que forma parte de su identidad, de su poder y limitación, y de su carácter expresivo. Además de afectar a la materialidad del cuerpo, la diversidad funcional constituye una experiencia vivida por la persona, aunque la misma, dado el poder expresivo del cuerpo (gestos, lenguaje), puede ser compartida intersubjetivamente. Puede añadirse que el conjunto de tales vivencias no puede quedar desligado del entorno social en que se desenvuelven las vidas de las personas con diversidad funcional; de ahí que Nussbaum considere como una cuestión de justicia que se construya un «entorno facilitador ${ }^{57}$ que libere sus vidas de la estigmatización.

2) Desde el punto de vista objetivo el cuerpo es conducta. Es el conjunto de acciones intencionales, de naturaleza psicoorgánica, desplegadas por el sujeto actuante en el mundo físico y social que le rodea. Mediante la realización de tales acciones, integradas en la conducta, el cuerpo se muestra objetivamente ante los otros. En ese sentido, podemos decir que la visión antropológica del cuerpo propuesta por Laín considera al ser humano desde su capacidad de obrar y al cuerpo como fundamento de la acción humana. P. Ricoeur ${ }^{58}$ subraya la importancia del poder obrar que, como fondo antropológico, caracteriza a la agencia. La visión lainiana de la agencia, de la capacidad de obrar propia de la realidad personal, deudora de la filosofía de Zubiri, remite al cuerpo en la interrelación de una triple dimensión ${ }^{59}$.

55 Laín Entralgo, P., Ser y conducta del hombre, o. c., pp. 238-242. Hughes y Paterson realizan una lectura política del sentimiento de sufrimiento que experiencian muchas personas con diversidad funcional, en tanto en cuanto se trata no solo de una experiencia sobre el impedimento, sino también de experiencias de sufrimiento ante los prejuicios y las barreras discapacitantes. Hughes, B. y PAterson, K., "El modelo social de la discapacidad y la desaparición del cuerpo», en: BARTON, L. (comp.): Superar las barreras de la discapacidad, o. c. Sobre la importancia del sentimiento compasivo ante la vulnerabilidad humana, de suma relevancia para la justicia con las personas con diversidad funcional, puede verse: CoRTINA, A., Ética de la razón cordial, Ediciones Nobel, Oviedo, 2007; Justicia cordial, Trotta, Madrid, 2010. Sobre la importancia política de la compasión en relación al apoyo de los ciudadanos a la aspiración a una sociedad justa con las personas con diversidad funcional puede verse: Nussbaum, M., Emociones políticas, Paidós, Barcelona, 2014.

56 Laín Entralgo, P., Ibid., pp. 42-43.

57 Nussbaum, M., El ocultamiento de lo humano: repugnancia, vergüenza y ley, Katz Barpal, Madrid, 2006, p. 364.

58 Ricoeur, P., Caminos del reconocimiento, Trotta, Madrid, 2005, pp. 144.

59 Laín Entralgo, P., El cuerpo humano. Teoría actual, o. c., pp. 233-235. Laín retoma expresamente el artículo de Zubiri «El hombre y su cuerpo» publicado en 1973 en Asclepio, 
a) El cuerpo como agente de sí mismo. Por ser un psicoorganismo, realiza una serie de actos, algunos más preponderantemente orgánicos (como la digestión o la respiración), otros preponderantemente psíquicos (como pensar) que se integran en la acción realizada (por ejemplo, saludar a un amigo). En dichos actos subyacen una serie de procesos biofísicos y bioquímicos, cuyo conocimiento viene proporcionado por la ciencia positiva (anatomía, fisiología, psicofisiología, etc.). Esta es la dimensión que ineludiblemente entronca a la agencia con la naturaleza, de forma que la diversidad funcional —en tanto que afección corporal — tiene cierta repercusión en la agencia. No obstante, la necesidad que plantea Laín de adoptar una consideración antropológica del cuerpo humano (soma) exige la integración de esta dimensión con las demás, al tiempo que requiere tener presente la pluridimensionalidad que caracteriza la corporalidad humana. La diversidad funcional no podría, pues, verse meramente como una mera afección de la materialidad natural del cuerpo humano. Resulta más acertado, siguiendo a Laín, considerar que el cuerpo humano es materia personal y, en consecuencia, se hace necesaria una visión de la diversidad funcional, en tanto que afección corporal, como parte integral y constitutiva de la persona ${ }^{60}$, la cual puede realizar una acción, en un concreto contexto social, de un modo diferente al estadísticamente habitual (por ejemplo, se comunica mediante el lenguaje de signos).

b) El cuerpo como actor de sí mismo. Esta dimensión supone que la agencia no consiste en un mero obrar biológico (zoé) sino que también es un obrar biográfico (bíos). La agencia consiste en la integración biográfica de las distintas acciones - y los actos que, a su vez, las integran — realizadas a lo largo de la vida, de forma que quien las ejecuta puede ser observado como un actor o personaje, por cuanto representa un papel en la trama argumental que forma el conjunto de su vida. La agencia, como papel interpretado, está influida por la situación histórica y por las pautas sociales de comportamiento. La comprensión del obrar por parte de quien observa requiere de una labor hermenéutica sobre el papel desempeñado por el personaje. A su vez, el actor es también un intérprete de su propia biografía. P. Ricoeur ${ }^{61}$ señala que la categoría de personaje es una categoría narrativa, lo que supone que este elabora una identidad narrativa, aún cuando la misma quede mediada por la influencia histórica, sociocultural y por el encuentro intersubjetivo. De acuerdo con esta segunda dimensión, la diversidad funcional ha de ser contemplada desde su repercusión en la biografía personal y en la construcción de su identidad narrativa. Como tal, depende tanto de la interpretación que la persona afectada tenga de su propia biografía (identidad narrativa) como, de modo interrelacionado, de las interpretaciones que sobre tal biografía se atribuyan en el contexto histórico y sociocultural.

vol. XXV. Zubiri también trató esta cuestión, aunque con algunas diferencias, en el curso oral sobre «El problema del hombre» impartido en 1953-1954, recogido en la recopilación llevada a cabo por Ignacio Ellacuría y publicada póstumamente con el título Sobre el hombre, Alianza Editorial/Sociedad de Estudios y publicaciones, Madrid, 1986, Cap. X.

${ }_{60}$ «El problema de la personalización de la enfermedad nos ha conducido así al que en realidad constituye su nervio: la personalización del cuerpo, la vivencia y la concepción del cuerpo como parte integral y constitutiva de la vida personal», Laín ENTRALGo, P., Ser y conducta del hombre, o. c., p. 230.

${ }_{61}$ Ricoeur, P., Caminos del reconocimiento, o. c., p. 110. 
c) El cuerpo como autor de sí mismo. El tercer componente de la agencia se refiere a la libertad que se tiene en la ejecución de ciertas acciones, con los actos que estas conllevan, y en la realización de la vida que, en conjunto, se lleva. Se trata de una "libertad condicionada», influida por la naturaleza y por las circunstancias históricas y sociales. Dicha libertad se manifiesta en las decisiones ${ }^{62}$ tomadas que van configurando tanto la propia vida como la realidad personal.

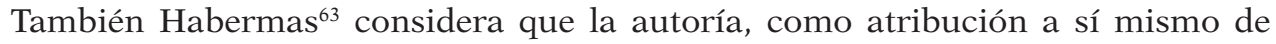
una acción, depende de la identificación del actor con su propio cuerpo, el cual tanto le capacita para actuar como le impone ciertos condicionamientos. Desde esta consideración de la agencia como autoría, la diversidad funcional representa un cierto condicionamiento de la libertad, de las opciones entre las que se puede elegir, en función también de la interacción del componente natural y el contexto histórico y social. En casos extremos, el condicionamiento natural puede suponer una anulación de la libertad, producida por el hecho de que la persona, en tanto que ser corporal, pierda la capacidad de decidir, lo que exige la introducción de la figura del representante.

3) Por último, Laín ${ }^{64}$ también asume, siguiendo a Lévinas, la perspectiva intersubjetiva, en tanto que el cuerpo-rostro del otro se hace éticamente presente en el encuentro inter-corporal. Esta perspectiva viene a mostrar que el cuerpo no es solo vivencia o materia personal; también es aquello que nos vincula al otro y nos abre a la alteridad. El encuentro interhumano es un encuentro inter-corporal. Lévinas tiene una visión ética del mismo: el encuentro con el rostro del otro me manifiesta la alteridad, pues el otro se me presenta como lo absolutamente otro. El rostro es la significación ética de un cuerpo que me demanda, que pide de mí ser entendido en la absoluta alteridad, respeto hacia la misma y atención a la menesterosidad que manifiesta (Laín cita las palabras de Lévinas: «el rostro en cuanto rostro es la desnudez y el desnudamiento del pobre, de la viuda, del huérfano, del extranjero»). El encuentro con el rostro del otro me responsabiliza de él, me obliga con él. Para Lévinas la expresión del rostro del otro remite al «no matarás». Al otro no solo se le mata físicamente sino también con la indiferencia afectiva o con su objetivación, es decir, no respetando su alteridad:

«Y así, lo que negativamente prescribe el "No matarás" es lo mismo que positivamente ordena este otro mandamiento: "Mirarás y tratarás con respeto la alteridad del otro". Desconocer o menoscabar esa alteridad, mirar y tratar al otro sin tener en cuenta la primaria condición de «otro» que su rostro me expresa, es en cierto modo matarle, proceder como si el "No matarás" hubiese sido prescrito ${ }^{65}$.

62 Laín Entralgo, P., El cuerpo humano. Teoría actual, o. c., p. 308.

63 Habermas, J., Entre naturalismo y religión, o. c., pp. 168-169.

64 Laín Entralgo, P., Ibid., pp. 235-243.

65 Ibid, pp. 242-243. 


\section{BaSES ANTROPOlÓGICO-MORALES DEL CUIDADO Y LA JUSTICIA CON LAS PERSONAS CON DIVERSIDAD FUNCIONAL}

Entendemos que la introducción de esta perspectiva del cuerpo por parte de Laín resulta relevante por cuanto la alteridad se concibe como diferencia ${ }^{66}$. La alteridad de la persona con diversidad funcional incluye su diversidad corporal, aunque esta no constituya la totalidad de aquella. El encuentro con un cuerpo-rostro me sitúa ante la obligación de respetar su diferencia corporal, evitando tanto su devaluación, al concebirla como deficiencia, como su objetivación despersonalizadora o la actitud de mera indiferencia. Por otra parte, debe entenderse que la menesterosidad que presenta su rostro no adquiere únicamente el sentido de una demanda de cuidado personal, sino que también expresa, en el ámbito de las instituciones, una demanda de justicia para poner fin a las barreras sociales existentes que dificultan los proyectos vitales. Además, como también señala Laín, habría que corregir la asimetría ética de la concepción levinasiana y entenderla como una relación de reciprocidad entre un yo y un tú, más acorde con la idea de igualdad que subyace a la concepción moderna de la justicia y con la conservación de la capacidad moral con que cuentan las personas en distintas formas de diversidad funcional.

Laín entronca la concepción del cuerpo-rostro levinasiana con la concepción del cuerpo como psicoorganismo que es agente, actor y autor de sí mismo, inspirada en Zubiri. Encuentra ${ }^{67}$ el punto de engarce entre las dos perspectivas del cuerpo en la idea zubiriana de que todos los seres humanos pertenecen biológicamente a un mismo phylum y en la necesidad de ayuda que hay en todo psicoorganismo humano, como se pone de manifiesto en la niñez:

«La tendencia a buscar la ayuda se convierte en algo bien determinado que temáticamente llamaremos socorro /.../ La necesidad que el organismo tiene, en tanto que animal, de los demás, es para el sentir intelectivo una necesidad de socorro, de socorrencia. La vida no es solo decurrencia y intercurrencia; desde el punto de vista de los demás hombres, a quienes sensitiva y orgánicamente estamos vertidos, es socorrencia /.../ La unidad entre el acudir y la ayuda es lo que expresa el concepto de socorrencia» ${ }^{68}$.

Que la vida es socorrencia significa, aplicado ahora al fenómeno de la diversidad funcional, que todo ser humano, como ser psicoorgánico, necesita ayuda en alguna etapa de su vida y esa demanda, expresada en forma de gestos o mediante el lenguaje, constituye una obligación moral para acudir a dar el cuidado. Ampliando esta idea zubiriana a un plano socio-político, tiene que significar también la existencia de una organización social justa que asuma las necesidades atípicas de las personas con diversidad funcional.

${ }_{66}$ Díaz, C., voz «alteridad»: en Moreno Villa, M. (dir.), Diccionario de pensamiento contemporáneo, San Pablo, Madrid, 1997.

67 Laín Entralgo, P., Ibid., pp. 235-243.

68 ZubiRI, X., Sobre el Hombre, Alianza Editorial/Sociedad de Estudios y Publicaciones, Madrid, 1986, p. 236. También Habermas parte del inacabamiento orgánico humano en el momento del nacimiento y concibe el comportamiento moral, desde un punto de vista antropológico, como un mecanismo para hacer frente a la vulnerabilidad humana, tanto social como corporal. HABERMAS, J., El futuro de la naturaleza humana, o. c., pp. 50-51. 
La concepción integral del cuerpo de Laín, formulada en un plano antropológicomoral, resulta productiva para iluminar el fenómeno de la diversidad funcional. Dicha concepción nos presenta el cuerpo del ser humano como materialidad personal y a la persona como un ser corporal en el que se funde lo natural, lo social, lo cultural, lo histórico y lo biográfico. El cuerpo humano es, para Laín, una presencia física que se despliega en una vida en socorrencia, una vida en interdependencia, abierto como está al encuentro intercorporal e intersubjetivo con los demás. Es en el encuentro con los otros en donde los cuerpos, con o sin diversidad funcional, se muestran como una presencia ética ${ }^{69}$. Por nuestra parte, interpretamos ${ }^{70}$ esta presencia ética desde la concepción normativa de la persona que encontramos en la ética kantiana y en la ética neokantiana del diálogo: la presencia ética de la persona en tanto que ser corporal no es sino el encuentro con la dignidad de un ser autónomo y vulnerable. Desde el enfoque normativo de la tradición kantiana podemos dar cuenta de la obligatoriedad moral del cuidado y de la obligatoriedad ético-política de la inclusión de las personas con diversidad funcional, cuyas bases antropológico-morales, a juicio de Laín, radican en la interdependencia de los cuerpos y de los sujetos encarnados.

\section{BiBLIOGRAFÍA}

Agra, M. X. (2013). «Vulnerabilidad, injusticias y cuidados», en: Boladeras, M. (ed.), Bioética: justicia y vulnerabilidad, Editorial Proteus, Cànoves y Samalús.

Aristóteles (1988). Política. Madrid: Gredos.

Armstrong, T. (2012). El poder de la neurodiversidad. Barcelona: Paidós.

Barton, L. (comp.) (1998). Discapacidad y Sociedad. Madrid: Morata, Madrid.

Barton, L. (comp.) (2008). Superar las barreras de la discapacidad. Madrid: Morata.

Canimas, J. (2015). “¿Discapacidad o diversidad funcional?», en: Siglo Cero, 46 (2), n² 254, pp. 79-97.

Conill, J. (2005). «¿Regreso a la “naturaleza humana”? Una reflexión bioética», en: López de la Vieja, M. T. (ed.), Bioética. Entre la Medicina y la Ética. Salamanca: Ediciones Universidad de Salamanca.

Cortina, A. (1996). «Éticas del deber y éticas de la felicidad», en: Gracia, D., (ed.), Ética y Estética en Xavier Zubiri. Madrid: Trotta.

Cortina, A..(2007. Ética de la razón cordial. Oviedo: Ediciones Nobel.

Cortina, A. (2010). Justicia cordial. Madrid: Trotta.

Cortina, A. (ed.) (2012). Guía Comares de neurofilosofía práctica. Granada: Comares.

Cortina, A. (2017). Aporofobia, el rechazo al pobre. Barcelona: Paidós.

Cortina, A. y Serra, M. (2016). Singulares. Ética de las tecnologías emergentes en personas con diversidad funcional. Madrid: Ediciones internacionales universitarias.

${ }^{69}$ Podría interpretarse que las nociones descriptivo-metafísicas lainianas son nociones de carácter «canon», es decir, no son únicamente un «es», sino también un «debe» al mismo tiempo.

${ }_{70}$ Entendemos que Laín incardina la visión ética del cuerpo de Lévinas en la filosofía moral de Zubiri que, como señala Cortina, se ocupa más de la descripción del hecho moral - moral como estructura - que de la moral normativa - moral como contenido-. Véase: Cortina, A., «Éticas del deber y éticas de la felicidad», en Gracia, D., (ed.), Ética y Estética en Xavier Zubiri, Trotta, Madrid, 1996, pp. 49-70. 
Crow, L. (1977). «Nuestra vida en su totalidad: renovación del modelo social dela discapacidad», en: Morris, J. (ed.), Encuentros con desconocidas. Feminismo y discapacidad. Madrid: Narcea.

Damasio, A. (2010). Y el cerebro creó al hombre. Barcelona: Destino.

Díaz, C. (1977). voz «alteridad», en: Moreno Villa, M. (dir.), Diccionario de pensamiento contemporáneo. Madrid: San Pablo.

Etxeberria, X. (2008). La condición de ciudadanía de las personas con discapacidad intelectual. Bilbao: Universidad de Deusto.

Feito, L. (2007). «Vulnerabilidad», en: Anales Sistema Sanitario Navarra, 30 (Supl. 3), 7-22.

Habermas, J. (2008). La inclusión del otro. Barcelona: Paidós.

Habermas, J. (2008). Entre naturalismo y religión. Barcelona: Paidós.

Habermas, J. (2009). El futuro de la naturaleza humana. Barcelona: Paidós.

Hughes, B. y Paterson, K. (2008). «El modelo social de la discapacidad y la desaparición del cuerpo», en: Barton, L. (comp.): Superar las barreras de la discapacidad. Madrid: Morata.

Laín Entralgo, P. (1968). Teoría y realidad del otro, I y II. Madrid: Revista de Occidente.

Laín Entralgo, P. (1991). El cuerpo humano. Teoría actual. Madrid: Espasa-Calpe.

Laín Entralgo, P. (1996). Ser y conducta del hombre. Madrid: Espasa Calpe.

Macintyre, A., Animales racionales y dependientes. Barcelona: Paidós.

Nussbaum, M. (2006). El ocultamiento de lo humano: repugnancia, vergüenza y ley. Madrid: Katz Barpal.

Nussbaum, M. (2007). Las fronteras de la justicia. Barcelona: Paidós.

Nussbaum, M. (2014). Emociones políticas. Barcelona: Paidós.

Ortega, F. (2010). El cuerpo incierto. Corporeidad, tecnologías médicas y cultura contemporánea. Madrid: CSIC.

Palacios, A. (2008). El modelo social de la discapacidad: orígenes, caracterización y plasmación en la Convención Internacional sobre los Derechos de las Personas con Discapacidad. Madrid: Ediciones Cinca.

Palacios, A. Y Romañach, J. (2006). El modelo de la diversidad. Madrid: Diversitas.

Ricoeur, P. (2005). Caminos del reconocimiento. Madrid: Trotta.

Seoane, J. A. (2011). "¿Qué es una persona con discapacidad?», en: Ágora. Papeles de Filosofía, 30/1, pp. 143-161.

Young, I. M. (2000). La justicia y la política de la diferencia. Madrid: Cátedra.

Zubiri, X. (1986). Sobre el Hombre. Madrid: Alianza Editorial/Sociedad de Estudios y Publicaciones.

[Artículo aprobado para publicación en enero de 2018] 